\title{
Assessment of Health-Seeking Behavior among Undergraduate Students at a University
}

\author{
Priya Reshma Aranha ${ }^{1}$ Melba Roshini Lobo ${ }^{2}$ Seema Patil ${ }^{3}$ \\ 1 Department of Child Health Nursing, Yenepoya Nursing College, \\ Yenepoya (Deemed to be) University, Mangaluru, Karnataka, India \\ 2 Department of Child Health Nursing, Yenepoya Nursing College, \\ Yenepoya (Deemed to be) University, Mangaluru, Karnataka, India \\ ${ }^{3}$ Department of Statistics, Yenepoya (Deemed to be) University, \\ Mangaluru, Karnataka, India \\ J Health Allied Sci ${ }^{\mathrm{NU}}$ 2022;12:385-391.
}

\begin{abstract}
Address for correspondence Melba Roshini Lobo, MSc, Department of Child Health Nursing, Yenepoya Nursing College, Yenepoya (Deemed to be) University, Mangaluru, Karnataka 575018, India (e-mail: melbaroshni@yenepoya.edu.in).
\end{abstract}

\begin{abstract}
Keywords

- students

- health-seeking behavior

- medical

- healthcare professionals
\end{abstract}

Background Students studying at a university of health sciences may have different perceptions regarding illness and treatment. Moreover, as they have access to healthcare, it may influence their health-seeking behavior. It is important to identify the health-seeking behavior of the students and to guide them accordingly.

Methods The present study was designed to assess the health-seeking behavior of undergraduate students. It was a cross-sectional descriptive study. A total of 236 students pursuing undergraduate courses in medicine, dentistry, nursing, and physiotherapy participated in the study. Checklist and perception scales were used to collect data that were then analyzed using descriptive and inferential statistics.

Results Use of the Internet to get information about illness, treatment, and medications (60.3\%; 139$)$, self-investigations $(50.6 \% ; 122)$ as well as self-medication practices $(54.4 \% ; 130)$ was commonly seen in students. Among the self-medications, antibiotics (63.7\%; 152), antipyretics (45.6\%; 109), analgesics (43.9\%; 104), and cough syrup (48.9\%; 116) were common. Regarding perception on health-seeking behavior, the majority $(49.3 \% ; 118)$ opined neutral for the statement that self-diagnosis is not wrong, $(49.4 \% ; 120)$ reported that over-the-counter medications can be taken, $(66.5 \% ; 157)$ agreed that keeping healthy by eating healthy can keep you away from the hospital. The barriers for health-seeking behavior, stigma, fear of confidentiality issues, fear of unwanted intervention, and unaware where to seek help were more commonly reported for mental healthcare-seeking behavior (odds ratio [OR]: $29.33,23.18,34.16$, and 11.96 , respectively), whereas issues relating to high cost, the long waiting hour in healthcare facility, and fear of side effects were reported for physical healthcare-seeking (OR: 9.80, 7.15, and 18.66, respectively) behavior.

Conclusion Self-investigation, self-medications, and use of the Internet to seek healthcare information are evident among students of university. Students exhibited different health-seeking behavior for physical and mental illnesses. Barriers to healthseeking also differed. Institutions should use this information for the effective usage of healthcare services by students. published online

February 9, 2022
DOI https://doi.org/ $10.1055 / \mathrm{s}-0041-1741413$. ISSN 2582-4287. (c) 2022. Nitte (Deemed to be University). All rights reserved.

This is an open access article published by Thieme under the terms of the Creative Commons Attribution-NonDerivative-NonCommercial-License, permitting copying and reproduction so long as the original work is given appropriate credit. Contents may not be used for commercial purposes, or adapted, remixed, transformed or built upon. (https://creativecommons.org/ licenses/by-nc-nd/4.0/)

Thieme Medical and Scientific Publishers Pvt. Ltd., A-12, 2nd Floor, Sector 2, Noida-201301 UP, India 


\section{Introduction}

Healthy habits and an active lifestyle are recognized as the most important factors influencing one's well-being. Healthcare professionals are not an exception to this. The student population at a healthcare facility are also the consumers of care. They get exposed to various facilities available in the hospital. At the same time, they start getting knowledge on preventive, curative, and rehabilitative care aspects. This may influence the healthcare-seeking behavior of students.

Health-seeking behavior refers to actions undertaken by a person who perceives himself to be ill to find an appropriate remedy. ${ }^{1}$ People seek help for health issues based on several reasons. The factors influencing the choice of treatment sources when symptoms occur may include sociocultural factors, social networks, gender, and economic status. The other determinants of health-seeking behavior are access to healthcare facilities in terms of cost of treatment and healthcare provider attitude. There are indications that the cost of prescribed medicines, poor access to facilities, and patient delays affect the patronage and utilization of public health services that increase the use of other treatment sources such as community pharmacies, drug peddlers, herbal medicine, religious or spiritual care organizations, and students in health-related academic disciplines. ${ }^{2}$ Information of healthseeking behavior and healthcare utilization has important policy implications in healthcare system development.

It is essential to understand the health-seeking behavior of students to maintain a healthy student community. There are barriers to seeking appropriate healthcare at the university health center for several reasons. It is believed that such knowledge would assist the university authority in the management and development of accessible and effective healthcare services to the students. ${ }^{3}$

The research conducted on doctors and medical students has demonstrated that healthy physicians set a strong example for their patients and have an improved ability to motivate their patients to change unhealthy behaviors. ${ }^{4-7}$ It is also seen that the personal health habits of medical students positively influence their counseling practices, for physical activity, ${ }^{8}$ as well as for smoking and drinking. ${ }^{9,10}$ These findings suggest that in promoting health in medical students, a novel approach to promote health in the general population may be developed.

Students of healthcare courses have different perceptions of symptoms and illness. Self-diagnosis and self-treatment are the common behaviors seen among medical students. ${ }^{11}$ They may develop their health-promoting lifestyle or health behaviors to keep up with good health.

A health-promoting lifestyle has been defined as a "multidimensional pattern of self-initiated actions and perceptions that serve to maintain or enhance the level of wellness, selfactualization, and fulfillment of the individual." ${ }^{12}$ It is also defined as any action taken by a person to maintain, attain, or regain good health and to prevent illness. Health behavior reflects a person's health beliefs. Exercising regularly, eating a balanced diet, and obtaining necessary inoculations are some of the health behaviors seen in healthcare professio- nals. ${ }^{13}$ In contrast, when an individual feels ill, then he or she adopts the sick role behavior. This behavior refers to all the activities designed to cure disease and restore health after a diagnosis has been made. Previous research studies done on health-seeking behavior among health providers found that the health habits of physicians are generally better than the rest of the population. ${ }^{14}$ It was seen that physicians are more likely to undergo routine checkups and timely investigations. ${ }^{15,16}$ Moreover, the majority of them do regular screening such as cholesterol level, blood pressure, breast examination, and colonoscopy. ${ }^{14}$ On the other hand, due to the prolonged working hours, some physicians have compromised their health behavior since they have less time to exercise and sleep. ${ }^{17}$

A study has shown that self-prescription was the most common practiced health-seeking behavior among 91.8 to $96.6 \%$ of the medical students followed by the order ignoring a health problem, seeking immediate care, using the Internet, reading more about the problem, and self-diagnosis and management. All these behaviors are practiced by more than $50 \%$ of the students. Factors affecting these behaviors mainly included self-care orientation and medical education. Other factors that had a role as well were gender, stage of studying, having a chronic illness, and lack of knowledge about the health services available. ${ }^{18}$

Another study described that medical students also had some issues regarding health-seeking behavior. Lack of time, unawareness about where to seek help, cost issues, and fear of future academic jeopardy were more common concerns among first-year students to the usage of mental health services, whereas issues of stigma were more commonly reported by final-year students for using mental health services. ${ }^{19}$ In a study it was also seen that $61.25 \%$ had taken treatment of which $74.69 \%$ visited a health facility for treatment, $19.21 \%$ took the home remedy, and $6.12 \%$ did not take any treatment. The place of treatment was decided by themselves in $20.81 \%$, whereas $78.78 \%$ of family members were decision makers. ${ }^{20}$

It was seen that in a study the majority of students (95.9\%) believed that nursing and medical courses helped them in altering their health behavior by gaining more understanding of the body functions and by increasing their awareness of certain diseases and medications. ${ }^{21}$ Students reported an average of 2.2 doctor visits over 12 months period. It was found that $31.3 \%$ had self-investigated and $66.3 \%$ had taken self-treatment. Around $38.4 \%$ of the students felt that it was alright to self-investigate, while $35.9 \%$ felt it was alright to take self-treatment. ${ }^{22}$ On the other hand, it was also seen that unhealthy behaviors are prevalent among medical students. ${ }^{23}$ It was also reported by $33 \%$ that they engaged in voluntary screening services. Further, $34.8 \%$ said that their health would improve if they engaged in health promotion activities. $^{24}$ Students identified lack of time, unawareness about where to seek help, cost issues, fear of future academic jeopardy, and issues of stigma were the barriers for using mental health services (odds ratio $[\mathrm{OR}]=2.87$ ). ${ }^{19}$

The investigators have come across the students of healthcare professionals exhibiting various behaviors to maintain 
good health. At the same time when they fall sick, they seek medical help available on campus. Thus, the investigators were interested to study the health-seeking behavior among undergraduate students studying in a healthcare university.

\section{Materials and Methods}

It was a cross-sectional study conducted among undergraduate students at a university that offers medicine, dentistry, nursing, physiotherapy, and other courses as well. A tertiary care multispecialty hospital and dental college hospital are providing a learning experience to the students within the campus. A quantitative approach and a descriptive design were used. The samples were randomly selected. Data was collected using Google form where the link was shared to the study participants using WhatsApp or email. A total of 236 students participated in the study.

After a thorough literature survey, the investigators developed a self-administered, predetermined structured questionnaire specifically for this study. It included a group of tools. Demographic proforma, checklist on health-seeking behavior of students, perception of students regarding health-seeking behavior which was a 5-point Likert scale, and a checklist on barriers for health-seeking behavior were used. A peer-review of the questionnaire was done for validation. All the tools were pretested and found reliable.

After obtaining approval from the institutional ethics committee (YEC-1/44/2021), permission was obtained from the concerned authority to conduct the study. Informed consent was obtained from the study participants and data was collected.

\section{Statistical Analysis}

Statistical analysis was performed using SPSS V.22.0 (IBM Statistical Package for the Social Sciences). Descriptive statistics were used for representing the demographic variables, health-seeking behavior, and for barriers of health-seeking variables, chi-squared test was used to find an association between perception and demographic variables, ORs with confidence intervals (Cls) were also computed for barriers of health-seeking behavior ( $p<0.05$ is considered as significant).

\section{Result}

-Table 1 shows the demographic characteristics of the students.

\section{Health-Seeking Behavior of Students}

-Fig. 1 explains the health-seeking behavior of students: use of the Internet to get information about illness, treatment, and medications (60.3\%; 139); approaching immediate help when sick (65\%; 160); self-investigations (50.6\%; 122); and self-medication practices $(54.4 \% ; 130)$ commonly seen in students.

Among the self-medications, the common drugs taken by students often were antibiotics (63.7\%; 152), antipyretics (45.6\%; 109), vitamins (43.5\%; 105), minerals (35.9\%; 86),
Table 1 Demographic characteristics of the study participants

\begin{tabular}{|c|c|c|}
\hline SI. no & $\begin{array}{l}\text { Demographic } \\
\text { characteristics }\end{array}$ & $\begin{array}{l}\text { Frequency } \\
\text { (percentage) }\end{array}$ \\
\hline 1 & $\begin{array}{l}\text { Gender } \\
\text { - Male } \\
\text { - Female }\end{array}$ & $\begin{array}{l}40(16.9 \%) \\
196(83.1 \%)\end{array}$ \\
\hline 2 & $\begin{array}{l}\text { Course undergoing } \\
\text { - BSc Nursing } \\
\text { - MBBS } \\
\text { - BPT } \\
\text { - BDS }\end{array}$ & $\begin{array}{l}61(25.8 \%) \\
25(10.6 \%) \\
82(34.7 \%) \\
68(28.8 \%)\end{array}$ \\
\hline 3 & $\begin{array}{l}\text { Year of study } \\
\text { - First year } \\
\text { - Second year } \\
\text { - Third year } \\
\text { - Fourth year }\end{array}$ & $\begin{array}{l}55(23.3 \%) \\
51(21.6 \%) \\
49(20.8 \%) \\
81(34.3 \%)\end{array}$ \\
\hline 4 & $\begin{array}{l}\text { Having a close family } \\
\text { remember in a health } \\
\text { profession } \\
\text { - Yes } \\
\text { - No }\end{array}$ & $\begin{array}{l}110(46.6 \%) \\
126(53.4 \%)\end{array}$ \\
\hline 5 & $\begin{array}{l}\text { Preferred source for treatment } \\
\text { - Allopathy } \\
\text { - Homeopathy } \\
\text { - Ayurveda } \\
\text { - Others }\end{array}$ & $\begin{array}{l}81(34.3 \%) \\
82(34.7 \%) \\
64(27.1 \%) \\
9(3.9 \%)\end{array}$ \\
\hline 6 & $\begin{array}{l}\text { Decision maker for } \\
\text { treatment seeking } \\
\text { behavior } \\
\text { - Self } \\
\text { - Family members } \\
\text { - Friends } \\
\text { - Teachers }\end{array}$ & $\begin{array}{l}134(56.8 \%) \\
98(41.5 \%) \\
3(1.3 \%) \\
1(0.4 \%)\end{array}$ \\
\hline
\end{tabular}

analgesics (43.9\%; 104), cough syrup (48.9\%; 116) herbal medications (32.5\%; 77), topical applications like Vicks (53.6\%; 127), Amrutanjan (27.4\%; 65), Iodex (14.3\%; 34), and tiger balm (29.5\%; 94).

Surprisingly, the students have also consumed ginger-pepper-mint extract, ginger tea, fenugreek seeds, turmeric, Holy Basil (tulsi), dry ginger, honey, medicinal herbs, lime, cumin, carom seeds (ajwain), Plectranthus amboinicus (Indian Borage), and Aloe Vera for various health issues. Many practiced drinking boiled warm water, steam baths, bathing in neem water, steam inhalation, and steam baths for health reasons.

\section{Perception Regarding Health-Seeking Behavior}

The majority $49.3 \%$ (118) opined neutral for the statement that self-diagnosis is not wrong, $49.4 \%$ (120) reported that over-the-counter medications can be taken, 28.7\% (69) reported that they would prefer the doctor of the same gender, $40.7 \%$ (96) said that friends and family are not the reliable sources for deciding treatment, 69.1\%(165) disagreed for the statement that self-treatment is the best treatment, 66.5\% (157) agreed that keeping healthy by eating healthy can keep you away from the hospital, 47.9\% (115) disagreed that web resources are as important as a doctor during sickness, 65.3\% (156) reported that the cost of 


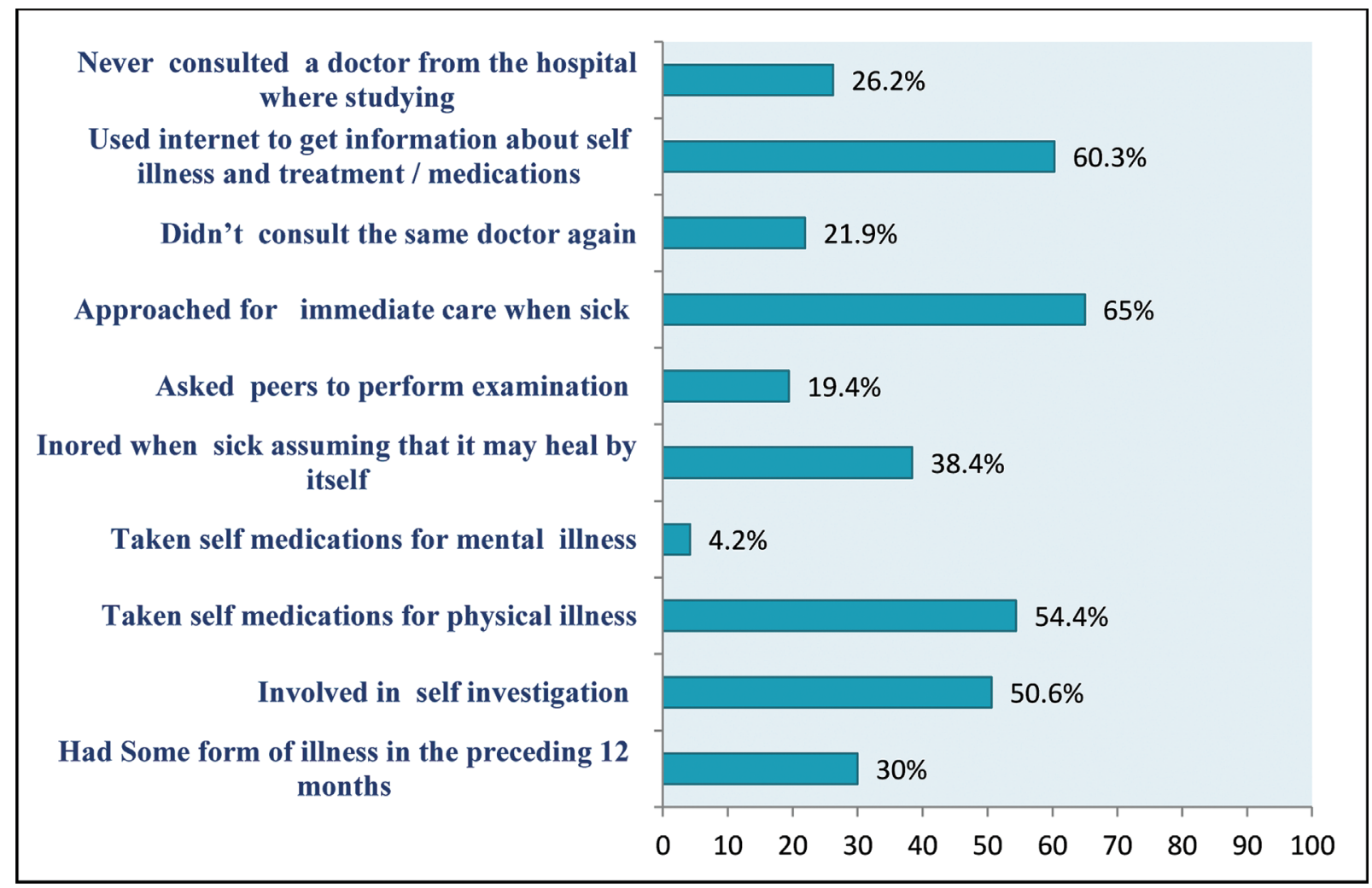

Fig. 1 Health-seeking behavior of students.

healthcare was not a matter to seek healthcare, 70.8\% (169) agreed that treating friends and peers without graduating or proper practice is wrong, and $57.6 \%(139)$ disagreed that there is no harm in attending classes during sickness.

\section{Perceived Barriers to Healthcare Seeking}

Fear of confidentiality, fear of unwanted intervention, and poor knowledge were the most common mental healthcare barriers reported (63.8\% [150], 67.4\% [159], 48.3\% [96]). In contrast, long waiting hours in healthcare facilities, fear of side effects, and fear of unwanted interventions were the most common barriers to physical healthcare-seeking (71.2\% [168], $66.9 \%$ [84], and 55.1\% [130]) of the participants, respectively. The mean number of barriers reported for mental healthcare seeking was 17.01, while the mean number of barriers for physical healthcare seeking was 10.97 . The type of barriers reported differed between mental and physical healthcare (-Table 2). While stigma, fear of confidentiality issues, fear of unwanted intervention, and unaware where to seek help were more commonly reported for mental healthcare-seeking (OR: 29.33, 23.18, 34.16, and 11.96, respectively) behavior, whereas high cost, long waiting hours in healthcare facility, and fear of side effects were observed (OR: 9.80, 7.15, and 18.66, respectively) barriers for physical healthcare-seeking. The fear of interference with academic performance did not differ significantly between the groups.

\section{Discussion}

Students of the healthcare profession gain extensive knowledge regarding health and healthcare through their courses. It is possible that the students would apply the information

Table 2 Barriers toward healthcare-seeking behavior

\begin{tabular}{|l|l|l|l|l|}
\hline Barriers & Mental health & Physical health & $x^{2}(p$-Value) & OR (95\% CI) \\
\hline Long waiting hour in healthcare facility & $152(64.4 \%)$ & $168(71.2 \%)$ & $42.81(0.000)$ & $7.15(3.83-13.34)$ \\
Fear of unwanted intervention & $159(67.4 \%)$ & $130(55.1 \%)$ & $97.71(0.001)$ & $34.16(14.44-80.83)$ \\
Unaware where to seek help & $142(60.2 \%)$ & $120(50.8 \%)$ & $67.09(0.000)$ & $11.96(6.29-22.72)$ \\
Fear of confidentiality & $150(63.8 \%)$ & $144(48.5 \%)$ & $81.50(0.003)$ & $23.18(10.33-52.04)$ \\
Stigma & $100(50.8 \%)$ & $84(42.6 \%)$ & $86.95(0.000)$ & $29.33(12.89-66.72)$ \\
Fear of side effect & $165(69.9 \%)$ & $158(66.9 \%)$ & $84.88(0.000)$ & $18.66(9.30-37.43)$ \\
High cost & $165(69.9 \%)$ & $148(62.7 \%)$ & $56.13(0.001)$ & $9.80(5.15-18.64)$ \\
Fear of absenteeism & $145(61.4 \%)$ & $120(50.8 \%)$ & $74.52(0.000)$ & $14.94(7.59-29.43)$ \\
Fear of impact on academic performance & $161(68.2 \%)$ & $126(53.4 \%)$ & $66.24(0.001)$ & $14.54(7.64-30.04)$ \\
\hline
\end{tabular}

Abbreviations: $\mathrm{Cl}$, confidence interval; OR, odds ratio.

All values are expressed as $n(\%)$, and $O R$ is given, $p<0.05$ considered as significant. 
they gain from their courses on themselves. As students are in the healthcare profession, their lifestyle may generally be better than that of the general population. ${ }^{25}$

In the present study, $30 \%$ of the students had some form of illness in the preceding 12 months and 38.4\% ignored their illness assuming that it may heal by itself. These findings are supported by a study that reported that a total of 112 (65\%) students visited hospital/clinic for their health problems and the reason given for not visiting the hospital/clinic was 12 (28\%) thinking that the problem was minor. The majority of 189 (80\%) students preferred university hospitals during health problems and parents were the first people for consultation 116 (49\%) during the illness.

Yet another study reported that health-seeking behavior among the students was quite commendable as $82 \%$ of them sought healthcare for minor and major illnesses from the same hospital setup, while the rest of them consulted a general practitioner and took self-medication. Out of the total 280 students, only $1.07 \%$ of the students did not consult anybody for the concerned ailments. ${ }^{26}$ It is also seen that students consulted their peers (37.5\%) in health-related academic disciplines rather than seeking treatment at the university health center. Some students (24.7\%) preferred community pharmacies, while others took personal responsibilities for their health or abstained from medical care for religious reasons $(16.8 \%)^{3}$

Among the study participants, 54.4\% (130) have taken self-medication for physical illness, 38.4\% (92) ignored sickness, 65\% (156) approached for healthcare immediately during illness, and $60.3 \%$ (145) used the Internet to get information about illness and treatment. Studies have reported that the prevalence of self-medication was found to be $55 \%$ among the medical students in Egypt, ${ }^{27} 76 \%$ among medical and nonmedical students in Pakistan, ${ }^{28}$ and $66.3 \%$, 92\%, 57.05\% at various places in India. ${ }^{3,22,26}$ Another study supports these findings where it was seen that $58.3 \%$ of medical students self-investigated, $95.80 \%$ took self-medications, $87.40 \%$ have ignored their sickness, $62 \%$ approached medical care immediately, and $57.90 \%$ used the Internet for information regarding health and medicine. ${ }^{18}$ It was also reported that medical students had higher levels of physical and psychological health problems and often tended to selfmedicate. $^{29-32}$

A study has reported that self-prescription was the most common practice of health-seeking behavior among 91.8 to $96.6 \%$ of university students ( $\mathrm{CI}$ of $95 \%$ ) followed by the order ignoring a health problem, seeking immediate care, using the Internet, reading more about the problem, and self-diagnosis and management. All are practiced by more than $50 \%$ of the students. A set of other behaviors was identified as well. Factors affecting these behaviors mainly included self-care orientation and medical education. Other factors that had a role as well were gender, stage of studying, having a chronic illness, and lack of knowledge about the health services available. The self-medications often consumed were antibiotics (63.7\%; 152), antipyretics (45.6\%; 109), vitamins (43.5\%; 105), and analgesics (43.9\%; 104). These findings are supported by a study where among the medical students, consumption of analgesics was found to be $31 \%$, vitamins $25 \%$, and antibiotics $19 \%{ }^{18}$

In the current study, $49.4 \%$ (120) reported that over-thecounter medications can be taken. These findings are contradicted by a study conducted on pharmacy students where they found a significantly negative attitude of pharmacy students toward medication. This may be because the students have started to develop a sort of contrasting attitude depending on the course they were pursuing. ${ }^{33}$ It was also said that it is not uncommon that pharmacy students focus more on identification and reporting of adverse events during their training, compared with medical students. ${ }^{34}$

The study identified several barriers reported by the students for seeking healthcare services, and the barriers differed for seeking help for mental and physical health problems. These findings are consistent with the findings of a study that reported that lack of confidentiality, fear of unwanted intervention, and poor knowledge about the location of mental health services were the most common mental healthcare barriers reported (by $61.2 \%, 56.4 \%$, and $50.3 \%$ of participants, respectively). ${ }^{35}$ In contrast, lack of time, fear of side effects, and fear of unwanted interventions were the most common barriers to physical healthcareseeking (reported by 59.0\% [152], 43.0\% [159], and 34.7\% [131] of participants, respectively). Stigma, confidentiality issues, lack of awareness about where to seek help, and fear of unwanted intervention were more commonly reported for mental healthcare-seeking (OR: 4.21, 4.01, 3.19, and 2.43, respectively) behavior, while issues relating to cost, lack of time, and fear of side effects were observed less frequently (OR: $0.45,0.46$, and 0.57 , respectively) reported for physical healthcare seeking. In comparison with physical health, students were more indifferent to their mental health issues and preferred self-diagnosis and informal consultations over formal documented care. ${ }^{19}$

It was also studied that confidentiality issues, issues relating to cost, lack of time, and fear of side effects may impede health-seeking behavior. ${ }^{35}$ Yet another study reported barriers like the cost of care, protracted waiting time, inadequate health information, the unfriendly attitude of healthcare workers, and drug shortage. ${ }^{3}$

\section{Conclusion}

University students undergoing courses such as medicine, dentistry, physiotherapy, and nursing have a good level of self-care that has been exhibited through their health-seeking behavior. Students approach medical help during sickness, are self-medicated for physical illness, and are involved in self investigations as well. They also browsed the Internet to get information about illness, treatment, and medications. Students have also expressed their concerns regarding barriers to health-seeking behavior. The findings also showed the relative use of available health services within the university. Initiatives to improve the students' access to university healthcare services and also to overcome barriers could be taken. Promotional activities may be initiated to inform and educate the students regarding rational use of medications and access to treatment at the healthcare facility. 


\author{
Sources of Support \\ Nil.

\section{Conflicts of Interest \\ Not stated}

\section{Acknowledgment}

Authors wish to thank Yenepoya deemed to be University Mangaluru for the support rendered during the study and also the participants for their whole hearted cooperation.

\section{References}

1 MacKian S. A review of health-seeking behaviour: Problems and prospects. Health Systems Development Programme. University of Manchester, Manchester; 2003: 3-4. Accessed December 16, 2021 at: https://assets.publishing.service.gov.uk/media/57a08d1de5 274a27b200163d/05-03_health_seeking_behaviour.pdf

2 Ward H, Mertens TE, Thomas C. Health seeking behaviour and the control of sexually transmitted disease. Health Policy Plan 1997; 12(01):19-28https://pubmed.ncbi.nlm.nih.gov/10166099 AccessedFebruary122020. Doi: 10.1093/heapol/12.1.19

3 Afolabi MO, Daropale VO, Irinoye AI, Adegoke AA. Health-seeking behaviour and student perception of health care services in a university community in Nigeria. Health 2013;5:817-824

4 Frank E. STUDENTJAMA. Physician health and patient care. JAMA 2004;291(05):637https://pubmed.ncbi.nlm.nih.gov/14762049 AccessedJanuary232020. Doi: 10.1001/jama.291.5.637

5 Frank E, Breyan J, Elon L. Physician disclosure of healthy personal behaviors improves credibility and ability to motivate. Arch Fam Med 2000;9(03):287-290https://pubmed.ncbi.nlm.nih.gov/ 10728118 AccessedJanuary192020. Doi: 10.1001/archfami.9.3.287

6 Howe M, Leidel A, Krishnan SM, Weber A, Rubenfire M, Jackson EA. Patient-related diet and exercise counseling: do providers' own lifestyle habits matter? Prev Cardiol 2010;13(04):180-185https://pubmed.ncbi.nlm.nih.gov/20860642 AccessedFebruary22020. Doi: 10.1111/j.1751-7141.2010.00079

7 Frank E, Segura C, Shen H, Oberg E. Predictors of Canadian physicians' prevention counseling practices. Can J Public Health 2010;101(05):390-395https://pubmed.ncbi.nlm.nih.gov/ 21214054 AccessedJanuary232020. Doi: 10.1007/BF03404859

8 Lobelo F, Duperly J, Frank E. Physical activity habits of doctors and medical students influence their counselling practices. $\mathrm{Br} J$ Sports Med 2009;43(02):89-92https://pubmed.ncbi.nlm.nih.gov/ 19019898 AccessedJanuary122020. Doi: 10.1136/bjsm.2008.055426

9 Frank E, Elon L, Spencer E. Personal and clinical tobacco-related practices and attitudes of U.S. medical students. Prev Med 2009; 49(2-3):233-239 https://europepmc.org/article/med/19576926 AccessedJanuary122020 Doi: 10.1016/j.ypmed.2009.06.020

10 Frank E, Elon L, Naimi T, Brewer R. Alcohol consumption and alcohol counselling behaviour among US medical students: cohort study. BMJ 2008;337:a2155https://pubmed.ncbi.nlm.nih. gov/18996938 AccessedJanuary122020. Doi: 10.1136/bmj.a2155

11 Shadbolt NE. Attitudes to healthcare and self-care among junior medical officers: a preliminary report. Med J Aust 2002;177(S1): S19-S20 https://pubmed.ncbi.nlm.nih.gov/12088497/ Accessed onFebruary142020 Doi: 10.5694/j.1326-5377.2002.tb04622.x

12 Walker SN, Sechrist KR, Pender NJ. The health-promoting lifestyle profile: development and psychometric characteristics. Nurs Res 1987;36(02):76-81https://pubmed.ncbi.nlm.nih.gov/3644262/ Accessed onFebruary 142020

13 Almutairi KM, Alonazi WB, Vinluan JM, et al. Health promoting lifestyle of university students in Saudi Arabia: a cross-sectional assessment. BMC Public Health 2018;18(01):1093https:// bmcpublichealth.biomedcentral.com/articles/10.1186/s12889- 018-5999-z AccessedFebruary172020. Doi: 10.1186/s12889018-5999-Z

14 Frank E, Brogan DJ, Mokdad AH, Simoes EJ, Kahn HS, Greenberg RS. Health-related behaviors of women physicians vs other women in the United States. Arch Intern Med 1998;158(04):342-348https://jamanetwork.com/journals/jamainternalmedicine/ fullarticle/191429 AccessedFebruary172020. Doi: 10.1001/ archinte.158.4.342

15 Bazargan M, Makar M, Bazargan-Hejazi S, Ani C, Wolf KE. Preventive, lifestyle, and personal health behaviors among physicians. Acad Psychiatry 2009;33(04):289-295https://pubmed.ncbi.nlm. nih.gov/19690108/ AccessedFebruary172020. Doi: 10.1176/appi. ap.33.4.289

16 Richards JG. The health and health practices of doctors and their families. N Z Med J 1999;112(1084):96-99 https://pubmed.ncbi. nlm.nih.gov/10210296/ AccessedFebruary182020

17 Hull SK, DiLalla LF, Dorsey JK. Prevalence of health-related behaviors among physicians and medical trainees. Acad Psychiatry 2008;32(01):31-38. Doi: 32/1/31 [pii] 10.1176/appi.ap.32.1.31 Accessed December 16, 2021 at: https://pubmed.ncbi.nlm.nih. gov/18270278/

18 Sawalha K, Sawalha A, Salih E, et al. Health seeking behavior among medical students in the University of Sharjah. J Pharm Pharmacol 2017;5:561-564 Accessed February 18, 2020 at http:// www.davidpublisher.com/Public/uploads/Contribute/ 597ef29c31975.pdf

19 Menon V, Sarkar S, Kumar S. A cross-sectional analysis of barriers to health-care seeking among medical students across training period. J Mental Health Hum Behav 2017;22:97-103 Accessed March 20, 2020 at https://www.jmhhb.org/article.asp? issn $=0971-8990$; year $=2017$; volume $=22$; issue $=2 ;$ spage $=97$; epage $=103$; aulast $=$ Menon

20 Baliga S, Naik VA, Mallapur MD. Treatment seeking behaviour of rural adolescent girls - a community based cross-sectional study. Int J Med Public Health 2012;2(02):23-27 Accessed March 20, 2020 at https://www.ijmedph.org/article/92

21 Fahda AA, Farida H, Abdulaziz B. Assessment of the health seeking behavior of senior nursing students in Saudi Arabia. J Educ Pract 2013;4(10):31-37 Accessed March 20, 2020 at https://www. iiste.org/Journals/index.php/JEP/article/view/5789

22 Vaz FS, Ferreira AM, Kulkarni MS, Perni SG, Dsouza D, Dsouza LC. Study of health seeking behavior among medical students in Goa, India. Asian J Med Cli Sci 2012;1(03):140-141 Accessed March 20,2020 at https://www.researchgate.net/profile/MS-Kulkarni/publication/

237102003_Study_of_health_seeking_behavior_among_medica1_students_in_Goa_India/links/00b7d51d8378559194000000/ Study-of-health-seeking-behavior-among-medical-students-inGoa-India.pdf

23 Van der Veer T, Frings-Dresen MHW, Sluiter JK. Health behaviors, care needs and attitudes towards self-prescription: a cross-sectional survey among Dutch medical students. PLoS One 2011;6 (11):e28038https://www.ncbi.nlm.nih.-

gov/pmc/articles/PMC3221693 AccessedMarch202020. Doi: 10.1371/journal.pone.0028038

24 Nebert MK, Agina BMO, Andre Y. Health behaviour among nurses working in public hospitals in Kakamega County, Kenya. Nurs Res Pract 2017;2017:4683189https://www.ncbi.nlm.nih.gov/pmc/articles/ PMC5804103 AccessedMarch202020. Doi: 10.1155/2017/4683189

25 Clément M, Jankowski LW, Bouchard L, Perreault M, Lepage Y. Health behaviors of nursing students: a longitudinal study. J Nurs Educ 2002;41(06):257-265https://pubmed.ncbi.nlm.nih.gov/ 12096774/ AccessedMarch212020

26 Hadaye RS, Dass R, Sujata L. Health status and health seeking behaviour among urban and rural nursing students of a tertiary care hospital: a comparative study. International Journal Of Community Medicine And Public Health, [S.l.], v. 5, n. 10, p. 4419-4422, sep. 2018. ISSN 2394-6040. doi:http://dx.doi.org/10.18203/2394- 
6040.ijcmph20183986.] Accessed December 16, 2021 at: https:// www.ijcmph.com/index.php/ijcmph/article/view/3505

27 El Ezz NF, Ez-Elarab HS. Knowledge, attitude and practice of medical students towards self medication at Ain Shams University, Egypt. J Prev Med Hyg 2011;52(04):196-200https://pubmed. ncbi.nlm.nih.gov/22442925 AccessedMarch212020

28 Zafar SN, Syed R, Waqar S, et al. Self-medication amongst university students of Karachi: prevalence, knowledge and attitudes. J Pak Med Assoc 2008;58(04):214-217https://pubmed.ncbi.nlm. nih.gov/18655436/ AccessedMarch212020

29 Ibrahim MB, Abdelreheem MH. Prevalence of anxiety and depression among medical and pharmaceutical students in Alexandria University. Alexandria J Med 2015;51(02):167-73 Accessed December 16, 2021 at: https://www.tandfonline.com/doi/full/10.1016/j.ajme.2014.06.002

30 Chew-Graham CA, Rogers A, Yassin N. 'I wouldn't want it on my CV or their records': medical students' experiences of help-seeking for mental health problems. Med Educ 2003;37(10):873-880https:// pubmed.ncbi.nlm.nih.gov/12974841/ Accessed March 302020

31 Ellen Rimsza M, Kirk GM. Common medical problems of the college student. Pediatr Clin North Am 2005;52(01):9-24, viihttps://pedclerk.uchicago.edu/sites/pedclerk.uchicago.edu/ files/uploads/Common\%20medical\%20problems\%20of\%20the\% 20college\%20student.pdf AccessedMarch302020
32 Banerjee I, Bhadury T. Self-medication practice among undergraduate medical students in a tertiary care medical college, West Bengal. J Postgrad Med 2012;58(02):127-131https://pubmed. ncbi.nlm.nih.gov/22718057/ AccessedMarch302020. Doi: 10.4103/0022-3859.97175

33 Ram D, Eiman N. A study of attitude toward medication and medical help-seeking among medical and pharmacy students. J Behav Health 2018;7(01):14-19 Accessed March 30, 2020 at http://www.jbehavioralhealth.com/articles/A\%20study\%20of\% 20attitude\%20toward\%20medication\%20and\%20medical\% 20help-seeking\%20among\%20medical\%20and\%20pharmacy\% 20students. Doi: 10.5455/jbh.20170509094104

34 Ahmad A, Patel I, Balkrishnan R, Mohanta GP, Manna K. An evaluation of knowledge, attitude and practice of Indian pharmacists towards adverse drug reaction reporting: a pilot study. Perspect Clin Res 2013;4:204-10. Doi: 10.4103/22293485.120168 Accessed March 30, 2020 at: https://pubmed.ncbi. nlm.nih.gov/24312887/

35 Menon V, Sarkar S, Kumar S. Barriers to healthcare seeking among medical students: a cross sectional study from South India. Postgrad Med J 2015;91(1079):477-482 https://pubmed.ncbi. nlm.nih.gov/26253923/ AccessedMarch302020 Doi: 10.1136/ postgradmedj-2015-133233 